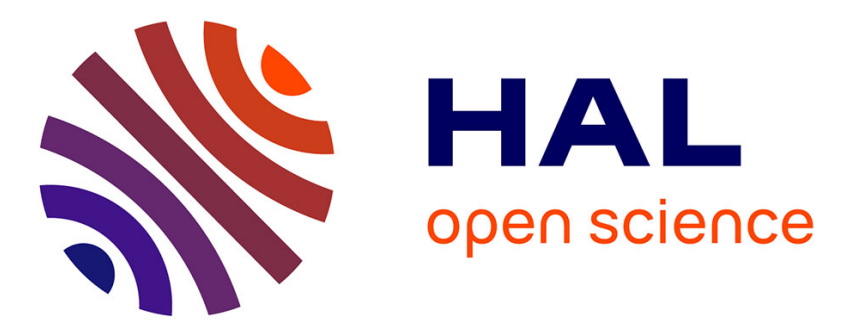

\title{
Toward Performance Guarantee for Autonomous Mobile Robotic Mission: An Approach for Hardware and Software Resources Management
}

\author{
Lotfi Jaïem, Lionel Lapierre, Karen Godary-Dejean, Didier Crestani
}

\section{- To cite this version:}

Lotfi Jaïem, Lionel Lapierre, Karen Godary-Dejean, Didier Crestani. Toward Performance Guarantee for Autonomous Mobile Robotic Mission: An Approach for Hardware and Software Resources Management. TAROS 2016 - 17th Annual Conference Towards Autonomous Robotic Systems, Jun 2016, Sheffield, United Kingdom. pp.189-195, 10.1007/978-3-319-40379-3_19 . lirmm-01310965

\section{HAL Id: lirmm-01310965 \\ https://hal-lirmm.ccsd.cnrs.fr/lirmm-01310965}

Submitted on 19 May 2016

HAL is a multi-disciplinary open access archive for the deposit and dissemination of scientific research documents, whether they are published or not. The documents may come from teaching and research institutions in France or abroad, or from public or private research centers.
L'archive ouverte pluridisciplinaire HAL, est destinée au dépôt et à la diffusion de documents scientifiques de niveau recherche, publiés ou non, émanant des établissements d'enseignement et de recherche français ou étrangers, des laboratoires publics ou privés. 


\title{
Toward Performance Guarantee for Autonomous Mobile Robotic Mission: An Approach for Hardware and Software Resources Management
}

\author{
Lotfi Jaiem, Lionel Lapierre, Karen Godary-Dejean, and Didier Crestani \\ Laboratoire d'Informatique Robotique et Microélectronique de Montpellier \\ \{jaiem, lapierre, Karen.Godary, crestani\}@lirmm.fr
}

\begin{abstract}
Mission performance is a large concept. It is rarely addressed in the context of autonomous mobile robotics. This paper proposes a generic framework addressing the concept of performance for autonomous mobile robotic mission. Moreover it presents an approach to manage the mobile robot hardware and software resources during the mission execution according to performance objectives. Simulation results illustrate the proposed approach on a patrolling mission example.
\end{abstract}

Keywords: Performance, resources management, autonomy, robot.

\section{Introduction}

True autonomy requires the ability to decide the way to perform a mission under performance constraints. It consists on choosing the appropriate resources according to the mission current situation. The robot must be also able to react if unexpected events occur like obstacle avoidance or resource failure [1] in order to keep guaranteeing the required performances. If the mission becomes unfeasible, the robot must be able to identify this situation and modify its objectives.

However the concept of performance is not clearly defined in robotics. Some works evaluate specifically the performance of a specific single-robot task, like human following [2] or performance assessment of a group of collaborative robots [3]. Industrial robotics defined many performance criteria like speed, repeatability, accuracy, etc. International standards (ANSI/RIA R15.05, ISO/9283) are defined too. However, some papers globally consider the mobile robot context. Cabelos et al. define in [4] performance metrics for mobile robot navigation. They propose a classification according to safety, trajectory quality and duration to accomplish a task. Several performance metrics are identified in [5] depending on mobile robotic task: SLAM, obstacle avoidance, grasping, etc. The problem of robotic mission guarantee is tackled in [6] using properties (liveness, safety) formal verification but the considered mission is still simple. Moreover nothing is proposed to overcome unforeseen problems during mission execution.

\section{Experimental Context}

A Pioneer $3 \mathrm{DX}^{\odot}\left(V_{R \max }=0.75 \mathrm{~m} / \mathrm{s}\right)$ integrating 16 sonars and 10 bumpers is used. 2 URG-04 LX Hokuyo used for obstacle avoidance, centering motion 
and robot localization. Localization is also performed using a Kinect ${ }^{(c)}$ camera $^{\circ}$ and geo-referenced QR-codes. The Kinect is also used for image capture. An embedded lead/acid battery generates up to $259 \mathrm{Wh}$ of energy. The robot communicates with an embedded laptop supporting a real time control architecture implementing the different algorithms. The laptop has its own battery, which is also monitored. Depending on algorithms and sensors used, 7 moving control laws, 3 localization methods and one image analysis control schemes (CS) are available.

The considered mission of 187 meters long is an autonomous patrolling to inspect the state (open/close) of two valves (V1-V2) (Fig. 1). Table 1 presents the mission decomposed into a sequence of $\left(n_{o b j}=9\right)$ objectives O: Go from docking station DS to the valve V1 (traveling), the robot rotates in the direction of V1 (turn toward), inspects it (image processing), and turns back. Then the robot travels from $\mathrm{V} 1$ to $\mathrm{V} 2$ and inspects the second valve. At the end, the robot goes back to DS. These objectives are performed using $n_{\text {task }}(\geq 1)$ concurrent $\operatorname{task}(\mathrm{s}) \mathrm{T}$ : Traveling objective needs both forward motion (FM) and location (L) tasks. One task (pure rotation $\mathrm{R}$ ) is needed for turning toward a valve. Image

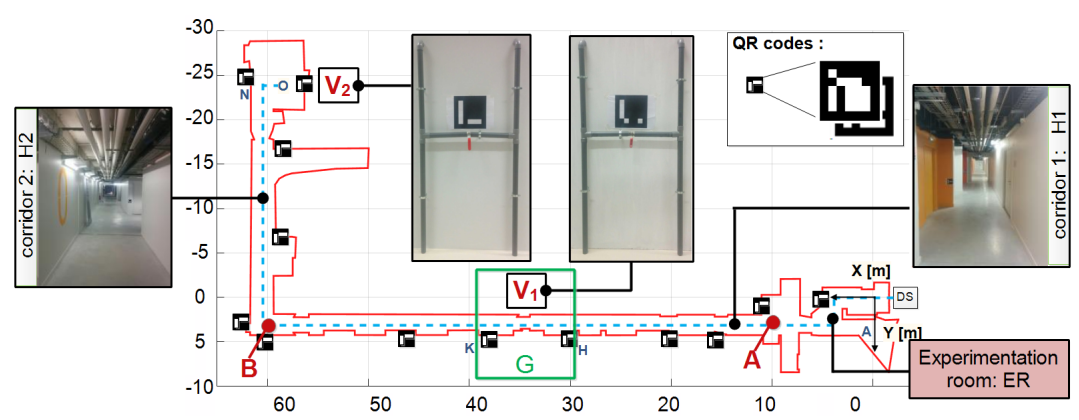

Fig. 1. Mission description

processing is done with only valve detection (VD) task. Tasks are performed usually with $n_{\text {opt }}(\geq 1)$ options (OT). 7 implemented OT to perform FM task. These are path following algorithms SMZ with different sensors $(S M Z-$ $U S, S M Z-L A S$, etc.). Location task L can be performed with 3 OT $(G O L$ is a Grid Oriented Localization technique based on laser data, $K I N$ is the QR code localization method or ODOmeter). An Alternative Implementation $A I$ corresponds to the selection, for an objective, a unique OT by task T. The number of alternatives $n_{\text {alt }}$ is the product of its corresponding $n_{\text {opt }}$. Different areas can be identified in Fig. 1. In H1, human can be encountered, but not in H2. A glazed area $\mathrm{G}$ is also present where sonars are crucial.

\section{Proposed Approach for Performance Management}

\subsection{Mission Performance: Which Relevant Viewpoints?}

We distinguish Main frame performance viewpoints which must be respected for all autonomous robotic missions: Safety, energy, localization and stability, from User's oriented ones like duration. 
The following performances constraints are defined for the studied mission: Duration axis $\left(\max D_{\text {perf }}=390 \mathrm{~s}\right)$, energy axis (robot energy: $\max E_{\text {perf } f_{R}}=$ $1.9 \mathrm{Wh}$ and laptop energy: $\max E_{\text {perf } f_{L}}=2 \mathrm{Wh}$ ), safety axis (Obstacle avoidance: $S_{\text {perf } f_{O A}}=$ True and harmlessness: $\max S_{p e r f_{H}}=4 J$ (maximum energy in case of impact with dynamic obstacles)).

Two Performance Margin classes are defined. Boolean margin characterizes a performance that can only be True or False. Continuous margin defines the gap between performance estimation (or observation) and objectives. The goals are to optimize continuous performance margins with regards to these objectives and to satisfy boolean margins.

\subsection{Performance Management: The Proposed Approach}

Preliminary Phase: The first step is to identify the performance inductors and to build performance estimation models allowing to predict the robot performances. To estimate the mission performance, a detailed representation of the Nominal Mission Plan (NMP) is needed. It is a sequence of $n_{a c t}\left(\geq n_{o b j}\right)$ Activities (Table 1 ). An activity $A_{k}^{c_{j}}$ is a part of a mission where an objective can be realized under a set of invariant constraints $c_{j}$. An activity can be performed using all its possible Alternative Implementations AI.

Table 1. Mission description/decomposition and complexity

\begin{tabular}{|c|c|c|c|c|c|c|c|c|c|c|c|c|c|c|c|c|c|}
\hline$x_{i-1}-x_{i}(\mathbf{m})$ & \multicolumn{3}{|c|}{$0-34$} & 37 & 37 & 37 & \multicolumn{4}{|c|}{$37-93.5$} & 93.5 & 93.5 & 93.5 & \multicolumn{4}{|c|}{$93.5-187$} \\
\hline Objective $O_{i}$ & \multicolumn{3}{|c|}{$\mathrm{DS} \rightarrow \mathrm{V} 1$} & $\circlearrowleft$ & $\bowtie$ & $\circlearrowright$ & \multicolumn{4}{|c|}{$\mathrm{V} 1 \rightarrow \mathrm{V} 2$} & $\circlearrowleft$ & $\bowtie$ & $\circlearrowright$ & \multicolumn{4}{|c|}{$\mathrm{V} 2 \rightarrow \mathrm{DS}$} \\
\hline$n_{\text {alt }_{i}}$ & \multicolumn{3}{|c|}{21} & 2 & 1 & 2 & \multicolumn{4}{|c|}{21} & 2 & 1 & 2 & \multicolumn{4}{|c|}{21} \\
\hline Task $T_{k}$ & \multicolumn{3}{|c|}{ FM / L } & $\mathrm{R} / \mathrm{L}$ & VD & $\mathrm{R} / \mathrm{L}$ & \multicolumn{4}{|c|}{$\mathrm{FM} / \mathrm{L}$} & $\mathrm{R} / \mathrm{L}$ & $\mathrm{VD}$ & $\mathrm{R} / \mathrm{L}$ & \multicolumn{4}{|c|}{ FM / L } \\
\hline$A_{k}^{c_{j}}$ & 1 & 2 & 3 & 4 & 5 & 6 & 7 & 8 & 9 & 10 & 11 & 12 & 13 & 14 & 15 & 16 & 17 \\
\hline$n_{\text {alt }}$ & 21 & 9 & 3 & 2 & 1 & 2 & 9 & 21 & 21 & 7 & 2 & 1 & 2 & 21 & 21 & 9 & 21 \\
\hline$\overline{V_{\max }(\mathrm{m} / \mathrm{s})}$ & & & & & & & & & & & & & & & & & \\
\hline
\end{tabular}

Off-line Performance Estimation: Once the NMP built, the objective is to estimate the nominal performance along the process, to determine the chosen alternative implementation $A I$ by activity, to specify the value of performance levers in order to respect the performance constraints. So, each $A I$ must be characterized with regard to each performance axis. The second condition is the ability to estimate the global performance of the NMP mission, by composing the local performance estimation for each eligible alternative implementation.

Following the off-line estimation phase, if performance constraints can be a priori satisfied, an alternative implementation can be selected for each activity. Initial Resources Allocation Solution is $R A S_{0}=\left\{A I_{0}, \ldots, A I_{n_{\text {act }}}\right\}$.

Online Performance Evaluation and Resources Management: According to the current $R A S$, an estimation of the current performance behavior is available and periodically compared with evaluated performance to decide if the 
mission remains feasible. However, a faulty hardware component or software module can disqualify the configuration of some current or future mission activities corresponding to an $A I$ using these faulty elements. A loss of time and energy (environment dynamism) can lead to negative performance margins. In order to consider these situations, the previous offline performance analysis is used online, on the remaining part of the mission, providing in real time a new set of alternative implementations to realize future activities (if it exits).

\section{Resources Management Implementation}

The mission plan being created, the mission duration $M_{D}$ is estimated by adding the $n_{a c t}$ duration of all $A_{k}$ activities. Activities could have predefined constant duration $d_{k}$ (static activities where $x_{k}=x_{k-1}$ ) or it can depend on the corresponding robot traveling length $\left(x_{k}-x_{k-1}\right)$ and velocity $V_{k}$.

Energy estimation models are experimentally identified and expressed in [7].

The mission safety viewpoint is implemented through two safety indicators: obstacle avoidance ability and safe traveling (harmlessness of the robot movement). So, for the considered robot, the following limitations must be respected:

- Sonars are the only efficient sensors in the glazed area $(\mathrm{G})$ (other sensors can be used also for obstacle avoidance). In this area $V_{\max }=0.46 \mathrm{~m} / \mathrm{s}$.

- Obstacle avoidance is required in the presence of human (H1 area). If lasers are used $V_{\max }=0.56 \mathrm{~m} / \mathrm{s}$.

- Area with no human presence (H2 area) $V_{\max }=V_{R \max }=0.75 \mathrm{~m} / \mathrm{s}$.

Resources management consists on determination for each activity, the $A I$ (algorithms and sensors) and its parameter(s) (robot velocity) that must be locally chosen for each activity to globally satisfy performance objectives.

For a mission, the Number of Global Alternatives $(N G A)$ is equal to the product of each number alternatives implementations $\left(n_{\text {alt }}\right)$ by the $n_{\text {act }}$ activities. It becomes quickly huge $\left(N G A>10^{13}\right.$ for Table 1$)$. It is a classical NP-hard Knapsack problem. To solve it in a real time context, the algorithm proposed in [8] has been adapted to the robotic context.

\section{Simulation Results}

The studied mission and robot system (cf. section 2) with $D, S$ and $E$ axes are now considered. Table 1 summarizes the mission description (Objectives $O_{i}$ ) and then mission decomposition (Activities $A_{k}$ ). Grey color expresses constant duration objectives. Projecting the $10 \mathrm{~m}$ length glazed area $(G)$ on the two ways mission is $[31,41 \mathrm{~m}]$ and $[146,156 \mathrm{~m}]$. Zone without human presence (H2) linear projection coordinates are [63.5, $123.5 \mathrm{~m}]$. These areas impact the constraints (maximum velocity and eligible $\{A I\}$ ) from safety viewpoint. Row $n_{\text {alt }}$ in Table 1 shows the number of AI by objective. $A_{k}^{c_{j}}$ row shows the number of activities by objective. $n_{\text {alt }}$ shows the number of $A I$ for the corresponding activities. It is reduced if some $A I$ are non illegible respecting safety constraints. The mission initially composed by 9 objectives is then composed by 17 activities with different constraints. Colored boxes in the last row express maximum linear 
velocity $V_{\max }$ depending on activities. In blue maximum velocity is $0.46 \mathrm{~m} / \mathrm{s}$, green $0.56 \mathrm{~m} / \mathrm{s}$, orange $0.75 \mathrm{~m} / \mathrm{s}$ and white $0 \mathrm{~m} / \mathrm{s}$ (pure rotation).

Once the decomposition is done, mission feasibility is tested considering the performance axes and a first resource allocation $R A S_{0}$ is calculated (Table 2).

Table 2. Generated resources allocation solutions

\begin{tabular}{|c|c|c|c|c|c|c|c|c|c|c|c|c|c|c|c|c|c||c||c|}
\hline$A_{k}$ & 1 & 2 & 3 & 4 & 5 & 6 & 7 & 8 & 9 & 10 & 11 & 12 & 13 & 14 & 15 & 16 & 17 & $N G A \geq$ & IT \\
\hline$R A S_{0}$ & 1 & 1 & 1 & 2 & 3 & 2 & 1 & 1 & 1 & 1 & 2 & 3 & 2 & 1 & 1 & 1 & 4 & $2 \cdot 10^{13}$ & 724 \\
\hline$R A S_{1}$ & & 1 & 1 & 2 & 3 & 2 & 1 & 1 & 1 & 1 & 2 & 3 & 2 & 1 & 1 & 1 & $\mathbf{5}$ & $1 \cdot 10^{12}$ & 651 \\
\hline$R A S_{2}$ & & & & & & & 1 & 1 & 1 & 2 & 3 & 2 & 1 & 1 & 1 & $\mathbf{6}$ & $1 \cdot 10^{9}$ & 499 \\
\hline$R A S_{3}$ & & & & & & & & & & & & & $\mathbf{7}$ & $\mathbf{7}$ & $\mathbf{7}$ & $\mathbf{7}$ & $1 \cdot 10^{4}$ & 187 \\
\hline
\end{tabular}

(5): SMZ-US/KIN, (6): SMZ-US/NONE, (7): CENTERING-2LAS-US/GOL

During the mission (Fig. 2), 8 obstacle avoidances $(O A)$ occur and energy (laptop and robot) and duration margins decrease (Fig. 3). Robot energy margin becomes negative twice (33 $\mathrm{m}$ and $62 \mathrm{~m}$ linear coordinates) and respectively two switches $R A S_{1}$ and $R A S_{2}$ were done to overcome these perturbations and ensure mission feasibility. Table 2 shows the details of the generated solutions ( $A I$ by activity), the global number of possible alternatives implementations $N G A$ and the number of iterations $I T$ needed to find a new solution.

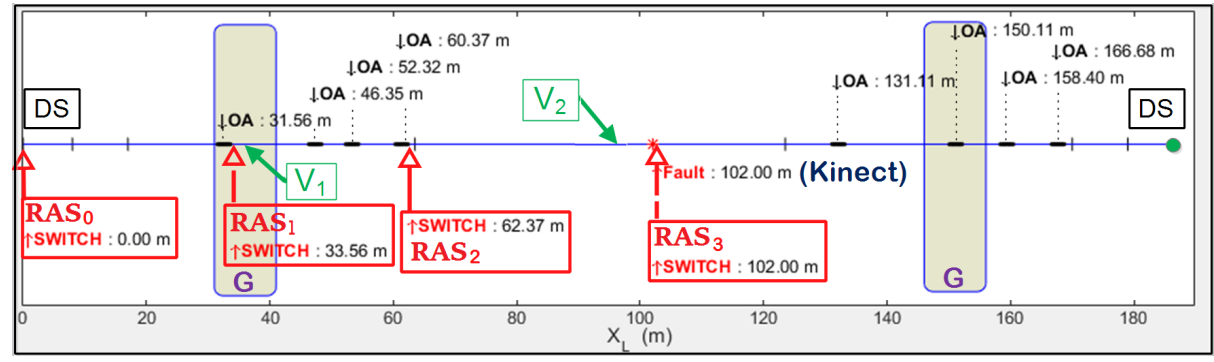

Fig. 2. Mission progress and events.

To overcome the energy loss during obstacle avoidance maneuver, the algorithm switch the selected $A I$ (initially $S M Z$ path following algorithm with two lasers and Kinect for $K I N$ localization) for the activity 17 to a less consuming OT with only sonars for $R A S_{1}$ and deactivating the Kinect for $R A S_{2}$ (localization based on odometer data).

At $102 \mathrm{~m}$, the Kinect fails. Since it is planned to be used in a future activities in $R A S_{2}$ for activities 14,15 and 16 , a new $R A S_{3}$ is found after eliminating/filtering the sets of $A I$ for the rest of activities. Robot energy margin increases because the new $R A S$ is less consuming than the previous one. Duration margin increases too. This is due to the localization method $G O L$ based on lasers data that allows the robot to run faster $\left(V_{k}=V_{R \max }=0.75 \mathrm{~m} / \mathrm{s}\right)$ than with Kinect $R A S_{0,1,2}$ (blurred image beyond $V_{k}=0.6 \mathrm{~m} / \mathrm{s}$ ). Margins increasing permits to tolerate the rest of the occurred obstacles avoidance. At the end, green boxes in Table 2 show the executed $A I$ along the mission. 


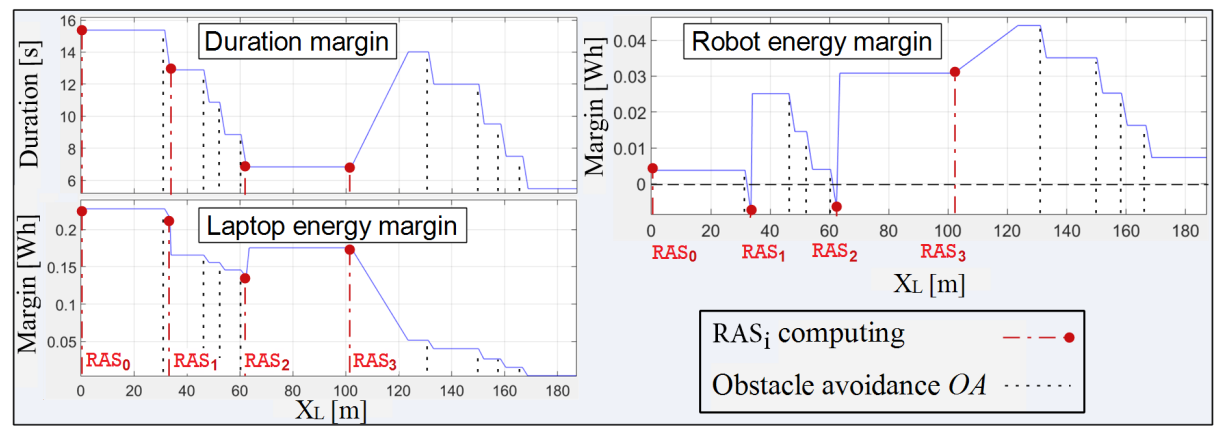

Fig. 3. Duration, laptop and robot energy margins.

\section{Conclusion}

This paper proposes a methodology for autonomous resources management and a conceptualization of performance on mobile robotics. Based on mission description and regarding to performance constraints, this methodology determines which hardware and software must be used for each mission activity. From different performance viewpoints, the proposed simulation demonstrates the complexity of the problem and the usability of the management methodology. The robot adapts dynamically its actual and/or planned resources allocation in order to satisfy all performance constraints under different types of internal (hardware or software failure) and external disturbing events. Future works will focus on experimental implementation of the proposed methodology.

\section{References}

1. Crestani, D.,Godary-Dejean, K., Lapierre, L.: Enhancing fault tolerance of autonomous mobile robots. Robotics and Autonomous Systems 68 140-155 (2015)

2. Doisy, G., Jevtic, A., Lucet, E., Edan, Y.: Adaptive Person-Following algorithm based on Depth Images and Mapping. IEEE/RSJ International Conference on Intelligent Robots and Systems (IROS); Vilamoura, Algarve, Portugal (2012)

3. Wellman, B.L., Erickson, B., Suriel, T., Mayo, K., Phifer, T., Acharya, K.: Effect of Wireless Signal Attenuation on Robot Team Performance, Proc. of the 27th int. Florida Artificial Intelligence Research Society Conference, pp. 412-417 (2014)

4. Cabelos, N.D.M., Valencia, J.A., Ospina, N.L.: Quantitative Performance Metrics for Mobile Robots Navigation. In Mobile Robots Navigation, edited by A. Berrera, ISBN 978-953-307-076-6, pp. 485-500 (2010)

5. Bonsignorio, F., Hallam, J., Del Pobil, A.P.: Good Experimental Guidelines. European Robotics Network NoE, pp. 1-25 (2008)

6. Lyons,D. M., Arkin, R. C., Nirmal, P., Jiang, S.: Designing autonomous robot missions with performance guarantees. IEEE Int. Conf. Intell. Robot. Syst., pp. 2583$2590(2012)$

7. Jaiem, L., Druon, S., Lapierre, L., Crestani, D.: A Step Toward Mobile Robots Autonomy: Energy Estimation Models. In: Proc. of the 17th Towards Autonomous Robotic Systems, Sheffield, U.K, (2016)

8. Bennour, M., Crestani, D., Crespo, O., Prunet, F.: Computer Aided Decision for Human Task Allocation with Mono and Multi Performance Evaluation. International Journal of Production Research, Vol. 43, No. 21, pp. 4559-4588 (2005) 